\title{
RIGID BODY DYNAMICS IN OPTIMIZATION OF THE MACHINE TOOL VIBROISOLATION
}

\author{
Radomir Slavković, Aleksandar Veg, Nedeljko Dučić, Nikola Slavković, Jelena Baralić, Ivan Milićević
}

Original scientific paper Modern design of the machine tool treats the suspending parts as a crucial element of the effective vibration isolation. Therefore the suspending items are specifically developed and subjected to extensive tests before being applied on real objects. These elements ensure accurate levelling and appropriate vibration damping. Usually selection of inadequate support element causes intensive disturbing effects in machining. The paper presents dynamics analysis of the machine tool suspended on flexible mountings. The overall analysis is conceived on a rigid body dynamics. This method enables selection of an optimal supporting configuration. Further on such an effective suspension design prevents a need for expensive monitoring of the dynamic characteristics of the mechanical system, i.e. machine tool and supports. The paper explores dynamics of a real, flexibly supported machine tool. Results are obtained with the assistance of the "SUPPORT" software. Finally the theoretical and computational statements are approved throughout extensive site measurements on the machine tool body with appropriate instrumentation.

Keywords: dynamics analysis; experiment; machine tool; software; transfer function

Dinamika sustava krutih tijela u optimizaciji vibroizolacije alatnih strojeva

Izvorni znanstveni članak Suvremeni razvoj alatnih strojeva tretira oslonce kao presudne elemente u vibroizolaciji. Zbog toga su oslonci posebno razvijeni i podvrgnuti opsežnim testovima prije primjene na realnim objektima. Oni osiguravaju precizno niveliranje i amortizaciju vibracija. Neodgovarajući izbor oslonaca uzrokuje neželjene efekte $u$ procesu obrade. Rad prezentira analizu dinamike alatnog stroja oslonjenog na fleksibilne oslonce. Ukupna analiza je koncipirana na dinamici krutih tijela. Ova metoda omogućava izbor optimalne konfiguracije oslanjanja. Ovako efikasan razvoj oslanjanja eliminira potrebu za skupim nadzorom strojnog sustava, tj. alatnog stroja i oslonca. U radu je dana analiza dinamike fleksibilno oslonjenog alatnog stroja u realnim uvjetima. Rezultati su dobiveni pomoću softvera SUPPORT. Konačno, teorijski i računarki rezultati potvrđeni su opsežnim mjerenjima na alatnom stroju, odgovarajućom mjernom opremom.

Ključne riječi: alatni stroj; dinamička analiza; eksperiment; softver; transfer funkcija

\section{Introduction}

Technical requirements for the contemporary products quality, as well as the compliance towards environmental protection regarding vibration and noise, imposed intensive research and development in machine tools dynamics. Focus of the machine dynamics studies is kept on spectrum signature and vibration severity during the machining process. As an inevitable side effect of machining arise vibrations. They cannot be totally eliminated, though significantly reduced to an acceptable level by appropriate methodology of vibroisolation. For that reason, a core aspect of the analysis is addressed to casing dynamics, shaft and bearing dynamics, transmitting items and other components of the tool machine. A machine tool can be submitted to either active or passive insulation from the vibrations. Both the cases should be studied under vibration insulation.

Simulations and modelling are the crucial techniques for successful solving the machine tool dynamics $[1,2]$, throughout Finite Element Method (FEM), Rigid Body Simulation Method (RBS) or a Combination of FEM and RBS. Altintas et al. (2005) presented structural analysis of the machine tools implementing finite element models and their experimental calibration techniques. Multi-body dynamic allows integrated simulation of machine kinematics, structural dynamics and control techniques, as discussed in [3]. Kono et al. (2010) developed Axis Construction Kit (ACK) in order to evaluate the configuration of machine tools. The ACK supports rigid body simulations and simple elastic body simulations [4]. Anayet et al. (2009) presented a consecutive procedure in experimental and analytical modal analysis applied in structural dynamic evaluation processes of a vertical machining centre [5]. Dhupia et al. (2006) presented kinematic and dynamic abilities of the machine, including the experimental frequency response functions (FRFs) and computed stability lobes of the machine in different configurations [6]. Lorenzer et al. (2009) presented efficient modelling and analysis of different machine configurations using encapsulated sub-models, called predefined structural module models [7]. Kono et al. (2010) presented a software tool which allows the evaluation of the performance and compliance with the design requirements for machine structure at an early stage of development [8]. Law et al. (2013) presented computationally efficient methodology which improves a dynamic performance of the machine tool even at the design stage [9].

The researches, discussed above in this paper justify the use of Rigid Body Simulation Method (RBS) in the dynamic analysis of the machine tool-support. Unlike the mentioned research, this paper reveals a new methodology aiming on the software for the simulation of dynamic characteristic of the elastic support. The validity of the created software has been confirmed by the site measurements.

\section{Dynamics of a mechanical system}

The first step in machine tool dynamic analysis is a structural modal analysis regarding one or more of three modelling methods: a) structure modelling by the lump masses; b) structure modelling by the finite elements; and c) structure modelling by the continuous beam.

Dynamic analysis of the machine tool, laid on a flexible mounting, is substantially based on a structure modelling by the box-shaped continuous beam. 
Substructure consists of other box-shaped beams of different densities. Their density depends on a size, shape, number and disposition of various items - gears, spindles, joints, holders, casing walls etc., $[11,16,17,18,19]$. Fig. 1 shows the example of a machine tool, modelled by the set of five rigid bodies, six flexible mountings and sixteen elastic interconnections.
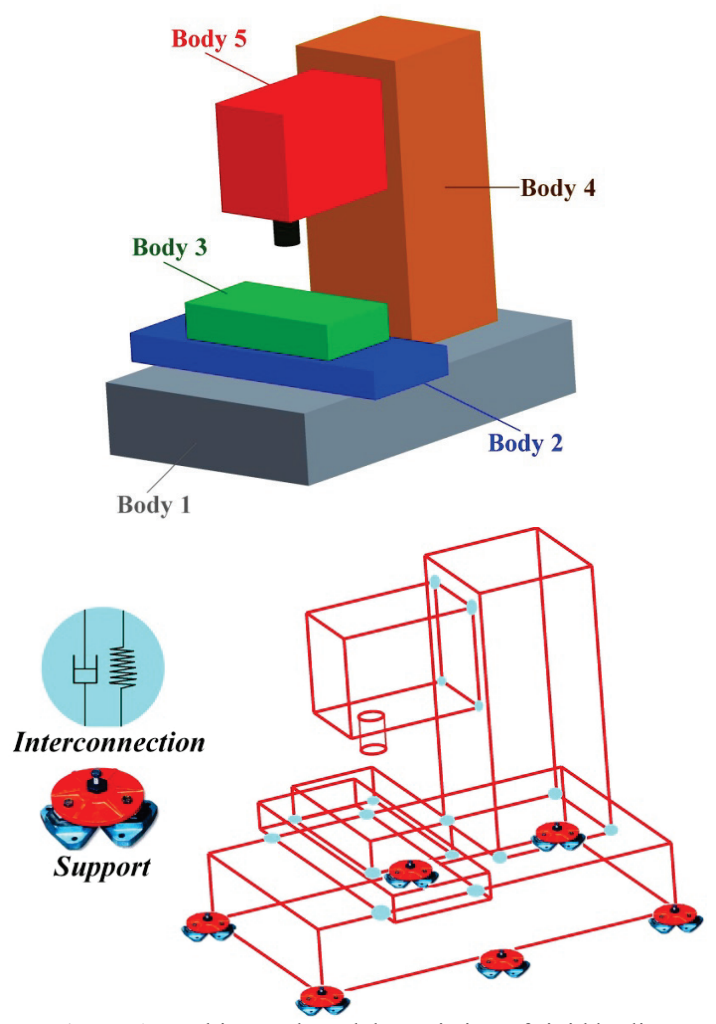

Figure 1 Machine tool model consisting of rigid bodies

\subsection{Differential equations}

The machining system laid on flexible mountings in operation obeys the damped oscillations motion. This motion is described by the Eq. (1), [10, 12, 14, 17].

$$
M \ddot{\delta}+B \dot{\delta}+C \delta=F
$$

where the symbols denote: $\boldsymbol{M}$ - mass matrix of the rigid body system; $\boldsymbol{B}$ - elastic-viscous damping matrix; $\boldsymbol{\delta}$ vector of generalized coordinates of rigid bodies inertia centres; $\boldsymbol{\delta}=\left(x_{1}, y_{1}, z_{1}, \boldsymbol{\varphi}_{x 1}, \boldsymbol{\varphi}_{y 1}, \boldsymbol{\varphi}_{z 1}, \ldots, x_{\mathrm{N}}, y_{\mathrm{N}}, z_{\mathrm{N}}, \boldsymbol{\varphi}_{x \mathrm{~N}}, \boldsymbol{\varphi}_{y \mathrm{~N}}\right.$, $\left.\boldsymbol{\varphi}_{z \mathrm{~N}}\right)^{\mathrm{T}} ; \dot{\boldsymbol{\delta}}$ - vector of generalized velocities of rigid bodies inertia centres; $\ddot{\boldsymbol{\delta}}$ - vector of generalized acceleration of rigid bodies inertia centres; $\boldsymbol{C}$ - matrix of stiffness of elastic-viscous joints $; \boldsymbol{F}$ - vector of generalized forces.

If the vector $\delta$ gets replaced with vector $\psi=\psi_{0} \mathrm{e}^{\lambda \phi^{t}}$ expressed by Eq. (2), the Eq. (1) transforms into the Eq. (3):

$$
\begin{aligned}
& \boldsymbol{\psi}=(\dot{\boldsymbol{\delta}}, \boldsymbol{\delta})^{\mathrm{T}}, \dot{\boldsymbol{\psi}}=(\ddot{\boldsymbol{\delta}}, \dot{\boldsymbol{\delta}})^{\mathrm{T}} \\
& \boldsymbol{A} \dot{\boldsymbol{\psi}}+\boldsymbol{D} \boldsymbol{\psi}=\boldsymbol{F}
\end{aligned}
$$

$$
\begin{aligned}
& \boldsymbol{A}=\left(\begin{array}{cc}
\boldsymbol{O} & \boldsymbol{M} \\
\boldsymbol{M} & \boldsymbol{B}
\end{array}\right) \\
& \boldsymbol{D}=\left(\begin{array}{cc}
-\boldsymbol{M} & \boldsymbol{0} \\
\boldsymbol{0} & \boldsymbol{C}
\end{array}\right) \\
& \boldsymbol{F}=\left(\boldsymbol{O} \boldsymbol{F}, \boldsymbol{F}_{f}\right)^{\mathrm{T}} \\
& \boldsymbol{O F}=(\boldsymbol{O} \boldsymbol{F})_{1, i}=0, i=1,2, \ldots, n \\
& \boldsymbol{F}_{f}=\left(\boldsymbol{F}_{f}\right)_{1, i}, i=1,2, \ldots, n
\end{aligned}
$$

where symbols denote: $n$ - degrees of freedom; $\boldsymbol{A}$ reduced mass matrix; $\boldsymbol{D}$ - reduced stiffness matrix, and $\boldsymbol{F}$ - load vector; $\lambda_{\phi}-$ natural (eigen) frequencies; $\psi_{0}-$ initial vector; $t$ - time. In the stated matrices, stiffness sub-matrix $\boldsymbol{C}$ is expressed by (8), i.e.:

$$
\boldsymbol{C}=\left(\begin{array}{ccccc}
\boldsymbol{C}_{i i} & \cdot & \cdot & \cdot & \boldsymbol{C}_{i N} \\
\cdot & \cdot & \cdot & \cdot & \cdot \\
\cdot & \cdot & \cdot & \cdot & \cdot \\
\cdot & \cdot & \cdot & \cdot & \cdot \\
\boldsymbol{C}_{N 1} & \cdot & \cdot & \cdot & \boldsymbol{C}_{N N}
\end{array}\right) .
$$

Matrix blocks $(\boldsymbol{C})_{j, k}(j, k=1,2, \ldots, N)$ are obtained from the Eq. (9).

$$
\left.(\boldsymbol{C})_{j, k}=\begin{array}{c}
\sum_{s \in N_{j}}\left(\boldsymbol{T}_{s}^{0}\right)_{P_{S}}^{C_{j}} \boldsymbol{C}_{s}^{s}\left(\left(\boldsymbol{T}_{s}^{0}\right)_{P_{S}}^{C_{j}}\right)^{\mathrm{T}}(j=k) \\
-\sum_{s \in N_{j, k}}\left(\boldsymbol{T}_{s}^{0}\right)_{P_{S}}^{C_{k}} \boldsymbol{C}_{s}^{s}\left(\left(\boldsymbol{T}_{s}^{0}\right)_{P_{S}}^{C_{j}}\right)^{\mathrm{T}}(j \neq k)
\end{array}\right\}
$$

Sub-matrices $\boldsymbol{C}_{s}{ }^{s}$ are obtained according to (10):

$$
\boldsymbol{C}_{s}^{s}=\left(\begin{array}{cccccc}
c_{x s} & 0 & 0 & 0 & 0 & 0 \\
0 & c_{y s} & 0 & 0 & 0 & 0 \\
0 & 0 & c_{z s} & 0 & 0 & 0 \\
0 & 0 & 0 & 0 & 0 & 0 \\
0 & 0 & 0 & 0 & 0 & 0 \\
0 & 0 & 0 & 0 & 0 & 0
\end{array}\right)_{s=1,2, \ldots, N_{0}},
$$

where symbols denote: $N$ - number of rigid bodies in the structure; $N_{0}$ - number of elastic joints in the structure; $\left(\boldsymbol{T}_{s}^{0}\right)_{P_{S}}^{C_{j}}$ - transformation matrix from the s-coordinate system (referred to the point of origin $P_{s}$ ) into the absolute coordinate system (zero point referred to $C_{j}$ ). Other transformation matrices are formed accordingly, i.e. $c_{x s}$, $c_{y s}, c_{z s}$ - the flexible mounting stiffness at the point $P_{s}$, orientation is along coordinate axes of the local coordinate system ( $s$-coordinate system).

Mass matrix is formed according to (11):

i.e. reduced dynamics equation, $[8,20]$ in which: 


$$
\boldsymbol{M}=\left(\begin{array}{ccccc}
\boldsymbol{M}_{1} & 0 & . & \cdot & 0 \\
0 & \boldsymbol{M}_{2} & \cdot & \cdot & 0 \\
0 & \cdot & \cdot & \cdot & \cdot \\
\cdot & \cdot & \cdot & \cdot & \cdot \\
\cdot & . & . & \cdot & \boldsymbol{M}_{\boldsymbol{N}}
\end{array}\right)
$$

where: $\boldsymbol{M}_{i}-$ matrix block composed in accordance with (12), $(i=1,2, \ldots, N)$

$$
\boldsymbol{M}_{i}=\left(\begin{array}{cccccc}
M_{i} & 0 & 0 & 0 & 0 & 0 \\
0 & M_{i} & 0 & 0 & 0 & 0 \\
0 & 0 & M_{i} & 0 & 0 & 0 \\
0 & 0 & 0 & J_{x x i} & J_{x y i} & J_{x z i} \\
0 & 0 & 0 & J_{y x i} & J_{y y i} & J_{y z i} \\
0 & 0 & 0 & J_{z x i} & J_{z y i} & J_{z z i}
\end{array}\right)_{i=1,2 \ldots . N}
$$

Matrix elements (12) are as follows: $M_{i}$ - mass of the $i$-rigid body, $J_{x x i}, J_{y y i}, J_{z z i}-$ axial inertia moments referred to the axes parallel to the absolute coordinate system whereby the axes cross their selves at the inertia centre of the $i$ - rigid body $\left(C_{i}\right)$, and have the same orientation as the absolute axes, $J_{x y i}=J_{y x i}, J_{x z i}=J_{z x i}, J_{y z i}=$ $J_{z y i}$ - centrifugal moments of inertia of the $i$ - rigid body for the axes parallel with the absolute coordinate system whereby the axes cross their selves at the inertia centre of the $i$-rigid body $\left(C_{i}\right)$, and have the same orientation as the absolute axes.

Damping matrix $\boldsymbol{B}$ and its sub-matrices are formed by the same mechanism as the stiffness matrix $\boldsymbol{C}$. Instead of the stiffness members $c_{x s}, c_{y s}, c_{z s}$ simply use appropriate damping members $b_{x s}, b_{y s}, b_{z s}$.

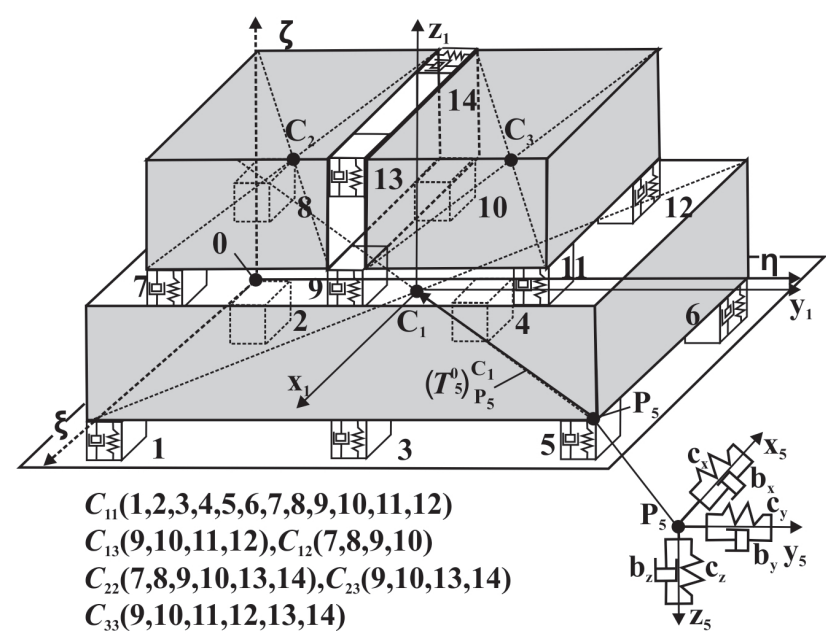

Figure 2 Tags for defining differential equations

In general, the overall transformation matrix from point $P_{s}$ of the local coordinate system $\left(x_{s}, y_{s}, z_{s}\right)$ into point $C$ of the absolute coordinate system $(\xi, \eta, \zeta)$ (Fig. 2) is performed as:

$$
\left(\boldsymbol{T}_{s}^{0}\right)_{P}^{C}=\left(\begin{array}{ll}
\boldsymbol{A T} & \boldsymbol{0 T} \\
\boldsymbol{B T} & \boldsymbol{A T}
\end{array}\right) .
$$

Sub-matrices in the transformational matrix $\left(\boldsymbol{T}_{S}^{0}\right)_{P}^{C}$ are as follows:

$$
\boldsymbol{A T}=\left(\begin{array}{lll}
a_{1} & a_{2} & a_{3} \\
b_{1} & b_{2} & b_{3} \\
c_{1} & c_{2} & c_{3}
\end{array}\right),
$$

$$
\begin{aligned}
& a_{1}=\cos \left(\xi, x_{s}\right), a_{2}=\cos \left(\xi, y_{s}\right), a_{3}=\cos \left(\xi, z_{s}\right) \\
& b_{1}=\cos \left(\eta, x_{s}\right), b_{2}=\cos \left(\eta, y_{s}\right), b_{3}=\cos \left(\eta, z_{s}\right) \\
& c_{1}=\cos \left(\zeta, x_{s}\right), c_{2}=\cos \left(\zeta, y_{s}\right), c_{3}=\cos \left(\zeta, z_{s}\right)
\end{aligned}
$$

$\boldsymbol{O T}$ - null matrix of $(3 \times 3)$ order

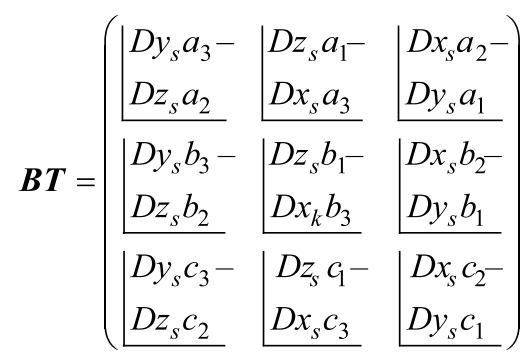

$$
\begin{aligned}
& D x_{s}=a_{1}\left(\xi_{C}-\xi_{P}\right)+b_{1}\left(\eta_{C}-\eta_{P}\right)+c_{1}\left(\zeta_{C}-\zeta_{P}\right) \\
& D y_{k}=a_{2}\left(\xi_{C}-\xi_{P}\right)+b_{2}\left(\eta_{C}-\eta_{P}\right)+c_{2}\left(\zeta_{C}-\zeta_{P}\right) \\
& D z_{k}=a_{3}\left(\xi_{C}-\xi_{P}\right)+b_{3}\left(\eta_{C}-\eta_{P}\right)+c_{3}\left(\zeta_{C}-\zeta_{P}\right)
\end{aligned}
$$

\subsection{Modal analysis}

When resolving the machine tool dynamics, deploying the conventional modal transformation $\boldsymbol{\mu}^{\mathrm{T}} \boldsymbol{B} \boldsymbol{\mu}$, ( $\boldsymbol{\mu}$ - modal matrix), the damping matrix $\boldsymbol{B}(1)$, cannot be reduced to a diagonal matrix due to damping capacity of supports. In such cases, system of differential equations would be coupled by velocities. In case of low damping rate, non-diagonal matrix elements in $\boldsymbol{B}$ become relatively small, causing minimal or negligible influence on damping. However, in machine tools, the relative ratio between $\Omega$ - excitation frequency and $\omega$ - system natural frequency should be kept above the following value $\frac{\Omega}{\omega}>\sqrt{2}$. This frequency separation would preserve self-amplified vibrations, where the non-diagonal members denote the influence on the force transfer to the soil. Hence, for the purpose of modal analysis it is advisable to replace matrices $\boldsymbol{M}, \boldsymbol{B}, \boldsymbol{C}$, with matrices $\boldsymbol{A}$ and $\boldsymbol{D}$ denoted in (4) and (5) respectively, and vector $\boldsymbol{\psi}$ denoted in (2). This substitution eases all further analysis where the matrices $\boldsymbol{A}$ and $\boldsymbol{D}$ can be reduced to diagonal matrices. The transfer function (29) is defined in a form of diagonal matrices at the supporting points. Modal analysis presented in this paper is based on the concept of a reduced dynamic equation of free damped oscillations (2), $[13,14,15,18]$.

An effective transformation of the dynamic Eq. (3) is accomplished applying a multiplication by the inverted matrix $\boldsymbol{A}^{-1}$. This yields the following (18): 


$$
A^{-1} A \dot{\psi}+A^{-1} D \psi=0
$$

If $\boldsymbol{E}$ stands for a unit matrix and $\boldsymbol{K}=-\boldsymbol{A}^{-1} \boldsymbol{D}$, then (18) transforms into (19):

$$
\left(\boldsymbol{K}^{-1}-\Lambda_{\phi} \boldsymbol{E}\right) \psi_{0}=\mathbf{0}
$$

The system of Eq. (19) has a nontrivial solution for $\psi_{0}$ if:

$$
\operatorname{det}\left(\boldsymbol{K}^{-1}-\Lambda_{\phi} \boldsymbol{E}\right)=0
$$

Solving the system of Eq. (20) an outcome contains $n$ pairs of eigenvalues (21):

$$
\left.\begin{array}{l}
\Lambda_{\phi j}=\theta_{j} \pm i \cdot v_{j}(j=1,2, \ldots \ldots . n) \\
\lambda_{\phi j}=\frac{1}{\Lambda_{\phi j}}(j=1,2 \ldots \ldots . n)
\end{array}\right\}
$$

The calculus might be conducted considering a high, low or zero damping rate. The low damping rate brings the complex conjugates of the eigenvalues $\left(\lambda_{\phi}\right)$ into machine tool dynamics. In that case system generates minor oscillations around the stable equilibrium position. The structure should remain non-symmetric throughout modelling, to evade appearance of multiple roots. Fortunately real structures are intrinsically asymmetric, which eases the analysis. Introduction of the system of Eq. (19) into eigenvalue relation (21) results with $n$-pairs of eigenvectors (22),

$$
\psi_{0}=\boldsymbol{\kappa} \pm i \cdot \varphi
$$

$\boldsymbol{\kappa}$ and $\boldsymbol{\varphi}$ are real and imaginary part of the original vector. If the solutions of the Eq. (19) are different complex conjugates, then the reduced mass matrix $\boldsymbol{A}$ and reduced stiffness matrix $\boldsymbol{D}$ can be transferred into a diagonal form. Hereby the Eq. (3) turns into global coordinates (26). The transformation is performed deploying the following matrices: modal complex conjugates $\mu_{\phi}$, eigenvectors $\psi_{0}$, and eigenvalues $\lambda_{\phi}$ in the following manner:

$$
\left.\begin{array}{l}
\psi_{0 z}\left(\lambda_{\phi r}\right)=\mu_{\phi_{z r}}(z=1,2, \ldots . .2 n),(r=1,2, \ldots .2 n) \\
\mu_{\phi_{z r}}=\boldsymbol{\mu}_{\phi R_{z r}}+i \boldsymbol{\mu}_{\phi I_{z r}}
\end{array}\right\}
$$

introducing a global coordinate vector $\boldsymbol{q}$ presented by (24) and (25):

$$
\begin{aligned}
& \boldsymbol{\psi}=\boldsymbol{\mu}_{\phi} \boldsymbol{q} \\
& \boldsymbol{\mu}_{\phi}=\left(\boldsymbol{\mu}_{\phi_{z 1}}, \boldsymbol{\mu}_{\phi_{z 2}}, \ldots \ldots \ldots \boldsymbol{\mu}_{\phi_{z 2 n}}\right) z=1,2, . ., 2 n
\end{aligned}
$$

Involving the values from above into the Eq. (3) and multiplying it on the left hand side by $\boldsymbol{\mu}_{\phi}^{T}$, yields a new Eq. (26),

$$
\boldsymbol{G} \dot{q}+\boldsymbol{H} q=\boldsymbol{\mu}_{\phi}^{\mathrm{T}} \boldsymbol{F}
$$

where the symbols denote: $\boldsymbol{G}=\boldsymbol{\mu}_{\phi}^{\mathrm{T}} \boldsymbol{A} \boldsymbol{\mu}_{\phi}-$ reduced diagonal mass matrix, $\boldsymbol{H}=\boldsymbol{\mu}_{\phi}{ }^{\mathrm{T}} \boldsymbol{D} \boldsymbol{\mu}_{\phi}-$ reduced diagonal stiffness matrix, $\boldsymbol{q}-$ global coordinate vector. Thus the eigenvalues are obtained as (27)

$$
\lambda_{\phi i}=-\frac{(\boldsymbol{H})_{i, i}}{(\boldsymbol{G})_{i, i}}(i=1,2, \ldots . .2 n)
$$

\subsection{Transfer function}

Transfer function (28) [16] comprises the relation between Laplace $\mathrm{z}$ - coordinate $\psi_{z}(i \Omega)$ and $p$ - Laplace transformation of the excitation force $F_{p}(i \Omega)$.

$[W(i \Omega)]_{p}^{z}=\frac{\psi_{z}(i \Omega)}{F_{p}(i \Omega)}=\sum_{r=1}^{2 n} \frac{\mu_{\phi p r} \mu_{\phi z r}}{(\boldsymbol{G})_{r r}\left(i \Omega-\lambda_{\phi r}\right)}$

As eigenvalues and vectors are considered as complex conjugates in this paper, the Eq. (28) transforms into the Eq. (29)

$[W(i \Omega)]_{p}^{z}=\sum_{r=1}^{2 n} \frac{\left(\mu_{\phi R_{p r}}+i \cdot \mu_{\phi I_{p r}}\right)\left(\mu_{\phi R_{z r}}+\mu_{\phi I_{z r}}\right)}{(\boldsymbol{G})_{r r}\left[i \Omega-\left(\theta_{r}+i \cdot v_{r}\right)\right]}$

where the following symbols denote: $\mu_{\phi R p r}, \mu_{\phi I p r}, \mu_{\phi R z r}$, $\mu_{\phi I z r}-$ real and imaginary part of respective vectors, $\theta_{r}, v_{r}$ - real and imaginary part of eigenvalues, $(\boldsymbol{G})_{r r}-$ diagonal members of the reduced diagonal mass matrix, $\Omega$ - excitation force frequency. For the convenience of analysis if $n<p \leq 2 n$, the displacements are deployed, otherwise, when $p \leq n$ the velocities are deployed. The stated frequency properties refer to the inertia centres of each rigid body of the modelled structure. Displacement of any point of the structure is described by the system of Eq. (30)

$$
\left.\begin{array}{l}
{\left[\xi_{P_{s}}(i \Omega)\right]_{p}^{\xi}=[W(i \Omega)]_{p}^{(e+1)}+[W(i \Omega)]_{p}^{(e+5)} \cdot z_{k}{ }^{t}-[W(i \Omega)]_{p}^{(e+6)} \cdot y_{k}{ }^{t}} \\
{\left[\eta_{P_{s}}(i \Omega)\right]_{p}^{\eta}=[W(i \Omega)]_{p}^{(e+2)}+[W(i \Omega)]_{p}^{(e+6)} \cdot x_{k}{ }^{t}-[W(i \Omega)]_{p}^{(e+4)} \cdot z_{k}{ }^{t}} \\
{\left[\zeta_{P_{s}}(i \Omega)\right]_{p}^{\zeta}=[W(i \Omega)]_{p}^{(e+3)}+[W(i \Omega)]_{p}^{(e+4)} \cdot y_{k}{ }^{t}-[W(i \Omega)]_{p}^{(e+5)} \cdot x_{k}{ }^{t}}
\end{array}\right\}
$$

where: $\left[\xi_{p_{s}}(i \Omega)\right]_{p}^{\xi}\left[\eta_{p_{s}}(i \Omega)\right]_{p}^{\eta}\left[\zeta_{p_{s}}(i \Omega)\right]_{p}^{\zeta}$ are the spatial displacements of the rigid body $(t=1,2, \ldots N, e=6(t$ $1)$, at point $P_{S}\left(s=1, \ldots, N_{0}\right)$, over absolute coordinate axes $\xi, \eta, \zeta$. The displacement is induced by the disturbance oriented along $p$-direction, referred to $x_{k}{ }^{t}, y_{k}{ }^{t}, z_{k}{ }^{t}$, local central coordinates at the point $P_{S}$. For the proper anchoring of the machine tools a vertical transfer of disturbances is predominantly important, since it determines the vibrations transfer to and from the soil. The coefficient of disturbances transfer from the machine to the floor is presented by the (31): 


$$
K_{p y}=\frac{\left|F_{y i}\right|}{\left|F_{p}\right|}=\frac{\left|c_{y i} \cdot y_{i}+b_{y i} \times \dot{y}_{i}\right|}{\left|F_{p}\right|}\left(i=1,2, \ldots . . N_{s}\right)
$$

where symbols denote: $F_{y i}-$ the force transferred vertically to the floor via $i$ - support, $F_{p}-p$-coordinate orientated disturbance, $K_{p y}$ - coefficient of the vertical disturbance transfer, $c_{y i}-$ stiffness of the vertical $i$-support , $b_{y i}$ - damping of the vertical $i$-support, $N_{s}$ - number of flexible mountings on the floor, $y_{i}$-displacement of the supporting point $i$, and $\dot{y}_{i}$-velocity of the point $i$. In the zones where the coefficient $K_{p y}<1$ an increase in vibrations has not been detected, which consequently means the suspension functions successfully.

\section{Application of modal analysis 3.1 Experimental setup}

The experimental survey has been realized on the universal lathe machine under active insulation from the vibrations (Fig. 3a). The set of applied instruments includes: 2, 3 - accelerometer Brüel \& Kjaer Type 4382 (operating frequency range $0,2 \mathrm{~Hz} \div 20 \mathrm{kHz}$ ), $\mathrm{C}$ - impact hammer PCB 086B20 (impact force $0 \div 500 \mathrm{lb}$, excitation frequency range $0 \div 27 \mathrm{kHz}$ ), D - amplifier Brüel \& Kjaer Type 2635 (frequency range $0,1 \mathrm{~Hz} \div 200 \mathrm{kHz}$ ), E signal analyser Hewlett Packard Type 3562A $(0 \div 100$ kHz), F - disc drive Hewlett Packard Type 9122C, Plotter Hewlett Packard Type 7090A.

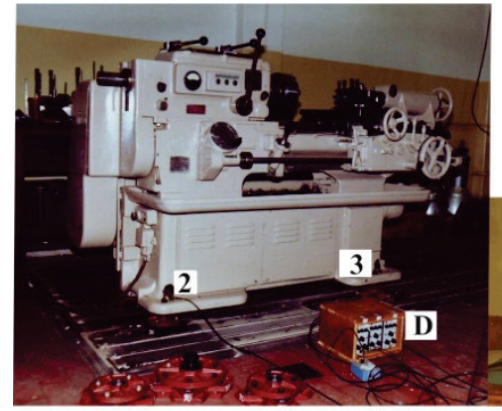

a)

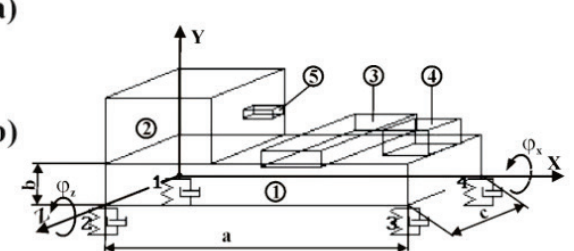

Ridid Body Model of a machine too

Figure 3 a) Flexibly supported machine tool; b) model of rigid body system

A rigid body structural modelling is conducted with a machine tool (lathe) shown in Fig. 3a. It is supported by four ES $3 \times 50$ flexible mountings (model shown in Fig. $3 b)$. Decomposed structure consists of the following five substructures: 1- lathe pedestal, 2 - main drive unit, 3 cross and longitudinal support, 4 - tailstock and 5 - drill chuck. They are flexibly interconnected, forming a single rigid body, laid on the ground over flexible mountings.

The set of parameters for the decomposed structure dynamic calculus is: assumed degrees of freedom (DOF): $y, \varphi_{x}, \varphi_{z}$, inner density rate $\left(\rho=7800 \mathrm{~kg} / \mathrm{m}^{3}\right) ; \rho_{1}$
$=0,5 \rho ; \rho_{2}=0,6 \rho ; \rho_{3}=0,5 \rho ; \rho_{4}=0,8 \rho ; \rho_{5}=0,5 \rho$; part dimensions $\left(a_{i}, b_{i}, c_{i}\right.$ in $\left.\mathrm{m}\right): a_{1}=2 ; b_{1}=0,5 ; c_{1}=0,7$; $a_{2}=0,7 ; \quad b_{2}=0,8 ; \quad c_{2}=0,7 ; \quad a_{3}=0,4 ; \quad b_{3}=0,2$; $c_{3}=0,9 ; \quad a_{4}=0,3 ; \quad b_{4}=0,3 ; \quad c_{4}=0,3 ; \quad a_{5}=0,2$; $b_{5}=0,1 ; c_{5}=0,1$.

The flexible mounting ES $3 \times 50$ shown in Fig. 4a consists of three elementary ES $1 \times 50$ mountings (Fig. 4b). Elementary Force to Deformation chart is shown in Fig. 4c. A rubber insert (50 Sh hardness) serves as a viscoelastic element.

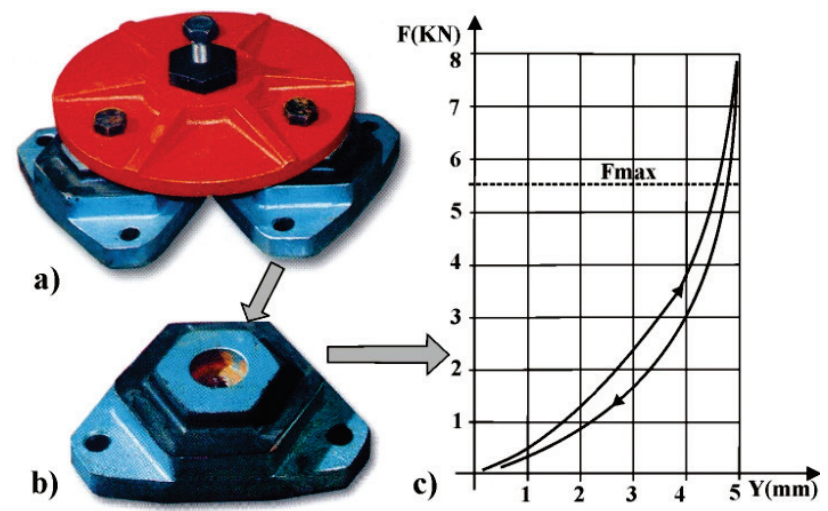

Figure 4 Flexible mounting: a) ES $3 \times 50$, b) elementary mounting ES $1 \times 50$, and c) Force to Deformation chart of ES $1 \times 50$

Support stiffness $c(\mathrm{~N} / \mathrm{m}): c_{x 1}=8 \times 10^{5}, c_{y 1}=1,5 \times 10^{6}$, $c_{z 1}=1 \times 10^{6}, c_{x 2}=8 \times 10^{5}, c_{y 2}=1,5 \times 10^{6}, c_{z 2}=1 \times 10^{6}, c_{x 3}=$ $8 \times 10^{5}, c_{y 3}=1,5 \times 10^{6}, c_{z 3}=1 \times 10^{6}, c_{x 4}=8 \times 10^{5}, c_{y 4}=$ $1,5 \times 10^{6}, c_{z 4}=1 \times 10^{6}$.

Damping rate $b(\mathrm{~N} \cdot \mathrm{s} / \mathrm{m}): b_{x 1}=1500, b_{y 1}=4000, b_{z 1}=$ $1500, b_{x 2}=1500, b_{y 2}=4000, b_{z 2}=1500, b_{x 3}=1500, b_{y 3}=$ $4000, b_{z 3}=1500, b_{x 4}=1500, b_{y 4}=4000, b_{z 4}=1500$.

\subsection{Results and discussion}

The first three natural modes shown in Fig. 5 refer to the undamped vibrations whereby the related natural frequencies $f_{0 i}$ are obtained from (32).

$$
f_{0_{i}}=\frac{1}{2 \pi \sqrt{\lambda_{\phi i}}}(i=1,2,3) .
$$

Depending on (32) $\lambda_{\phi i}$ are eigenvalues of undamped vibrations (given in (33)) obtained by the developed software system.

$\lambda_{\phi 1}=8,774 D-04$,
$\lambda_{\phi 2}=2,659-08$,
$\lambda_{\phi 3}=8,920 D-09$.

Displacements at the supporting points 2 and 3 are presented by their magnitude and phase vs frequency (Fig. 6). Displacement function, by its size and shape is identical for supports 1 and 4, due to structural symmetry, referred to OXY plane (Fig. 3b). 


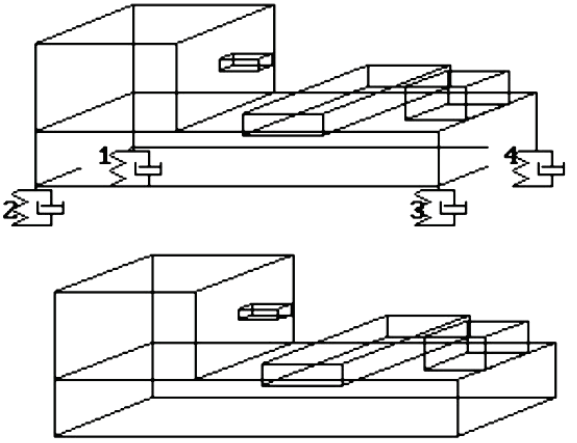

a) $\mathrm{f}_{01}=5.37 \mathrm{~Hz}$

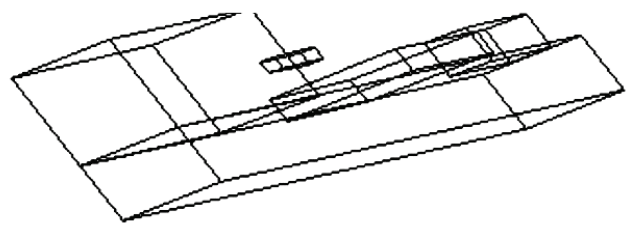

b) $\mathrm{f}_{02}=976 \mathrm{~Hz}$

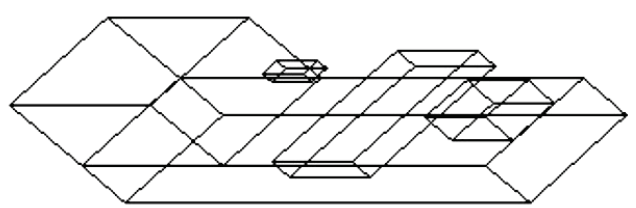

c) $\mathrm{f}_{02}=1690 \mathrm{~Hz}$

Figure 5 Dominant natural modes

Bode charts are plotted by the specifically developed software for machine dynamic analysis. When conducting the calculus of disturbance transfer to the floor, the nondiagonal members of the damping matrix were neglected. They were intentionally cancelled, since the damping coefficient of the rubber mounting (34) is extremely low $(\zeta \approx 0,065)$. In such cases, differential equations are uncoupled in respect to velocities.

$\zeta=\frac{b_{y}}{2 \sqrt{c_{y} m}}$

where the symbols denote: $b_{y} \quad(\mathrm{~N} \cdot \mathrm{s} / \mathrm{m})$ - damping coefficient along the $y$-axis, $m(\mathrm{~kg})$ - fraction of the total mass referred to appropriate support, $c_{y}(\mathrm{~N} / \mathrm{m})-$ stiffness coefficient along the $y$-axis.

Set of dominant vibration modes and frequency responses are determined by the application of 'SUPPORT' software, developed in Visual Basic ${ }^{\circledR}$. Other differential equations are being solved by IMSL subroutines for the eigenvalues and eigenvectors. Dynamic response at either point 2, 3 is identical for the fundamental spectral harmonic $\left(f_{01}=5,37 \mathrm{~Hz}\right)$.

Set of Figs. 7a, 7b, 7c, 7d, present plots of the displacement magnitude at respective supports 1, 2, 3 and 4 in the frequency range $(0 \div 50) \mathrm{Hz}$. Excitation force with impact test was adjusted to $F_{\mathrm{p}}=100 \mathrm{~N}$.

Spectral plot (Figs. 7a, 7b, 7c and 7d) shows the dominant peak in the range $(5 \div 6) \mathrm{Hz}$. Fortunately, the regular operating range of the lathe machine is far higher than $6 \mathrm{~Hz}$, which contributes to its outcome quality.

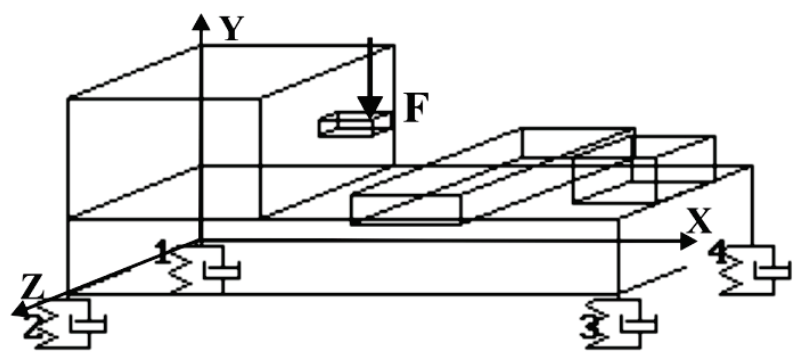

SUPPORT 2

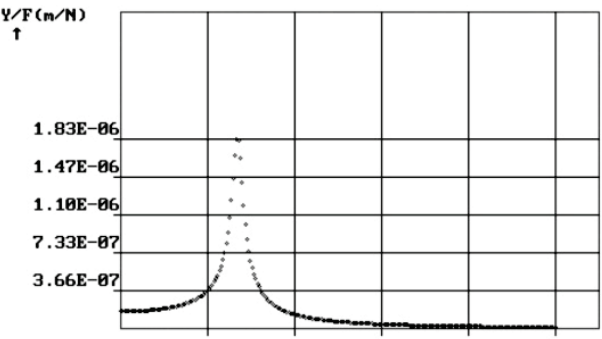

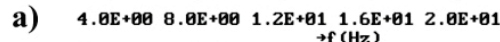
$K_{p} \max =2.84$

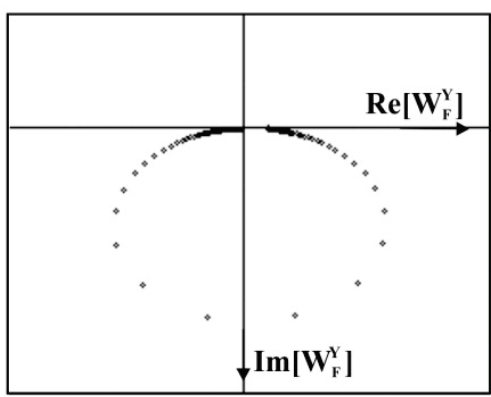

b)

SUPPORT 3
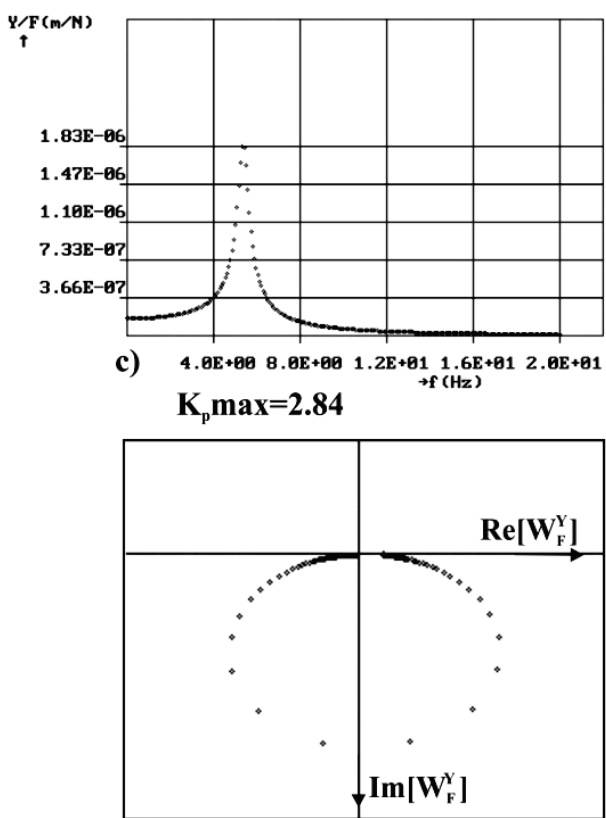

d)

Figure 6 Bode plot magnitude/phase: a), b) at flexible mounting 2 and c), d) at flexible mounting 3

Tab. 1 shows in parallel the results obtained by experimental measurements and the virtual, software analysis. Software generated amplitude-frequency characteristic for the points of the support 1 and 2 are identical as for 3 and 4 , as in real surrounding of the machine, on which the verification was performed $(0 \div 50$ 
$\mathrm{Hz}$ ), the influence of vertical Eigen frequency oscillation $f_{0}=5,37 \mathrm{~Hz}$ is dominant (Fig. 5a ).

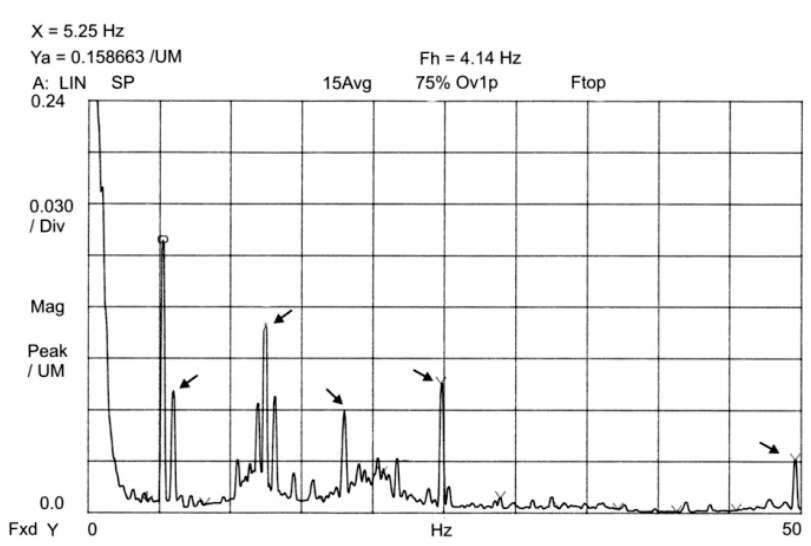

Figure 7a Spectral response plot, support 2

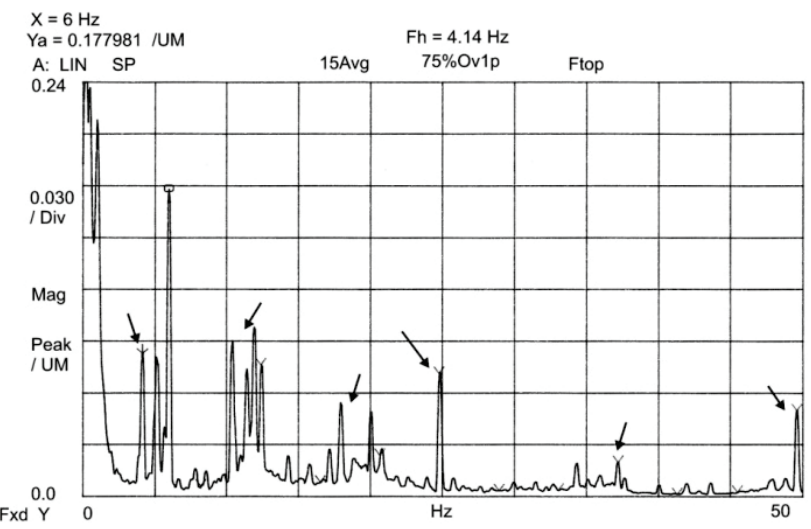

Figure 7b Spectral response plot, support 3

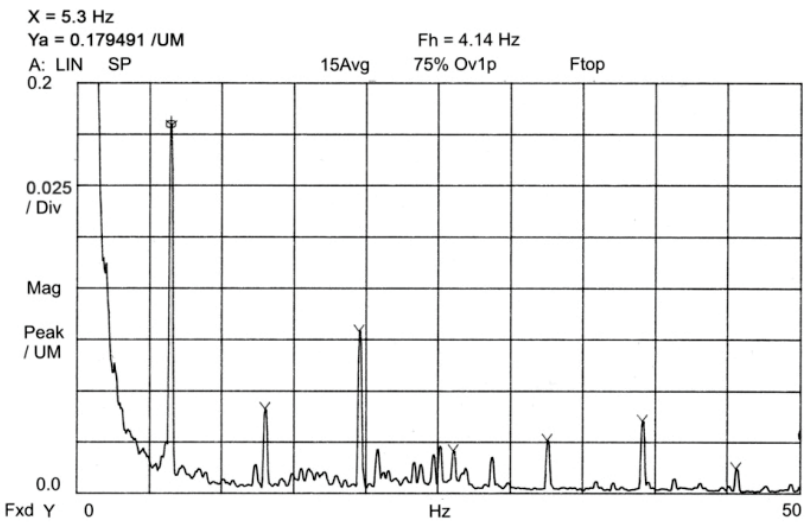

Figure 7c Spectral response plot, support 1

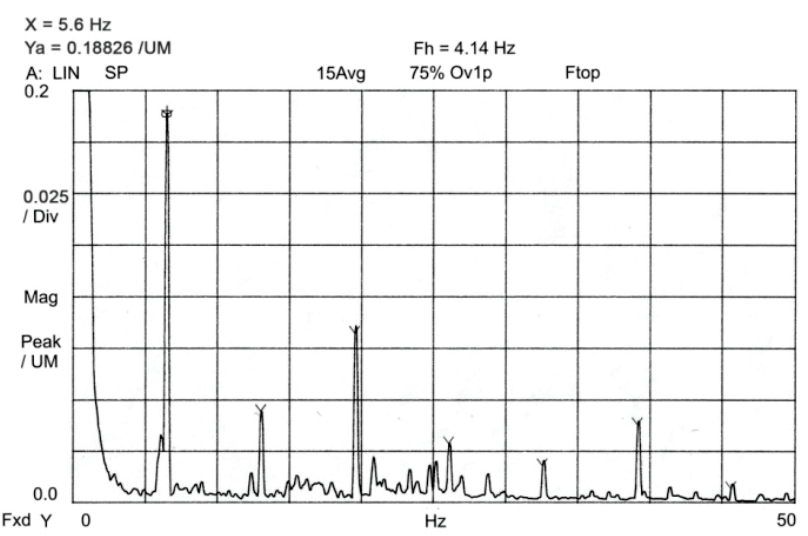

Figure 7d Spectral response plot, support 4
Table 1 A survey of the measured and processed results

\begin{tabular}{|c|c|c|c|c|c|}
\hline$\stackrel{\stackrel{0}{ٍ \pi}}{\stackrel{\pi}{>}}$ & 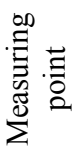 & 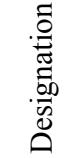 & 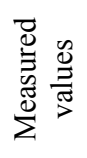 & 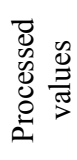 & 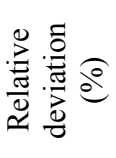 \\
\hline \multirow{4}{*}{ 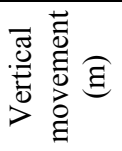 } & 1 & $y_{1 \max }$ & 0,179 & \multirow{4}{*}{0,183} & 2,1 \\
\hline & 2 & $y_{2 \max }$ & 0,159 & & 13,1 \\
\hline & 3 & $y_{3 \max }$ & 0,178 & & 2,7 \\
\hline & 4 & $y_{4 \max }$ & 0,188 & & 2,7 \\
\hline \multirow{4}{*}{ 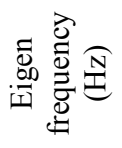 } & 1 & $f_{01}$ & 5,3 & \multirow{4}{*}{5,37} & 1,3 \\
\hline & 2 & $f_{02}$ & 5,25 & & 2,2 \\
\hline & 3 & $f_{03}$ & 6 & & 11,7 \\
\hline & 4 & $f_{04}$ & 5,6 & & 4,3 \\
\hline
\end{tabular}

A series of peaks which can be observed on measured amplitude frequency characteristics (Figs. 7a, 7b, 7c, 7d) are due to looseness in the machine structures (the machine is relatively old) and considerable influence of the environment (measuring was performed in the surroundings of machines which were in operation during the site measurements. Similarly, in the vicinity exists the tramway line).

\section{Conclusion}

Based on a modal analysis that has been conducted throughout this paper, the SUPPORT software for the simulation of machine tool support dynamics, has been developed. This dedicated software is inspired by a theory of Multi-body dynamics, as well as the software IWF Axis Construction Kit (Institute of Machine Tools and Manufacture, ETH-Zurich) aimed for the simulation of the Machine tool dynamics. The software has been used in the first stage of selecting the elastic supports for the machine tool, deployed in the simulation of the dynamic behaviour of any possible type of elastic support. Such an approach enables the selection of the most appropriate supports by their dynamic characteristics. Also, most probably, after setting the machine up on the supports chosen by this method, it would be unnecessary to adjust or verify applied suspension. Referring to the site measurements the software results diverge within $(2 \div 13)$ $\%$, which is a good convergence according to common engineering practice. The real operating range of the machine is $(10 \div 50) \mathrm{Hz}$, thus the frequency characteristic, in the machining process does not intensify the vibrations which can be transmitted over the support to the soil, i.e. the coefficient of the transmissibility is $K_{\mathrm{p}}$ $<1$. Further researches are planned to point on discrete models and sub-models, providing to the SUPPORT software a larger applicability on models with extended rate in degrees of freedom.

\section{References}

[1] Deng, W. J.; Xie, Z. C.; Li, Q.; Lin, P. Finite Element Modelling and Simulation of Chip Breaking with Grooved Tool. // International Journal of Simulation Modelling. 12, 4(2013), pp. 264-275.

[2] Harih, G. Decision Support System for Generating Ergonomic Tool-Handles. // International Journal of Simulation Modelling. 13, 1(2014), pp. 5-15. 
[3] Altintas, Y.; Brecher, C.; Weck, M.; Witt, S. Virtual machine tool. // Annals of the CIRP. 54(2), (2005), pp.115.

[4] Kono, D.; Lorenzer, Th.; Weikert, S.; Wegener, K.: Evaluation of modelling approaches for machine tool design. // Precision Engineering. 34, (2010), pp. 399-407.

[5] Anayet, U. P.; Waleed, F. F.; Nurul, A. K. M.; Loh, S. K. Dynamic Modal Analysis of Vertical Machining Centre Components. // Advanced in Aciustic and Vibration. (2009). URL: http://dx.doi.org/10.1155/2009/508076.

[6] Dhupia, J.; Powalka, B.; Katz, R.; Ulsoy, G. A. Dynamics of the arch-type reconfigurable machine tool. // International Journal of Machine Tools \& Manufacture. 47, (2007), pp. 326-334

[7] Lorenzer, T.; Weikert, S.; Wegener, K. Efficient Modelling and Simulation of Reconfigurable Machine Tools Using Predefined Structural. // 3rd International Conference on Changeable, Agile, Reconfigurable and Virtual Production, 2009.

[8] Kono, D.; Lorenzer, Th.; Weikert, S.; Wegener, K Comparison of Rigid Body Mechanics and Finite Element Method for Machine Tool Evaluation. // Institute for Machine Tools and Manufacturing (IWF), Zurich, Switzerland, 2010.

[9] Law, M,; Altintas, Y.; Phani, A. S. Rapid evaluation and optimization of machine tools with position-dependent stability. // International Journal of Machine Tools \& Manufacture. 68, (2013), pp. 81-90.

[10] Bishop, R. E. D.; Gladwell, M. L.; Michaelson, S. The Matrix Analysis of Vibration. // Cambridge University Press, 2008.

[11] Krodkiewski, J. Mechanical Vibration. The University of Melbourne, Department of Mechanical and Manufacturing Engineering, 2008.

[12] De Silva, C.W. Vibration and shock handbook. CRC Press, Taylor \& Francis Group, 2005.

[13] Hatch, M.R. Vibration Simulation Using MATLAB and ANSYS. Chapman \& Hall/CRC, 2001

[14] Graham, S. K. Fundamentals of Mechanical Vibrations. McGraw-Hill Companies, 2000.

[15] Gawronski, W. Dynamics and Control of Structures: A Modal Approach. Springer-Verlag New York, Inc., 1998.

[16] Kalajdzic, M. The Finite Elements Method. Faculty of Mechanical Engineering, University of Belgrade, 1984.

[17] Weck, M. Werkzeugmaschinen, Band 2, VDI-Verlag GmbH, Düsseldorf, 1981.

[18] Wenqing, Y.; Guangming, W.; Rongying, S.; Hongxing, H.; Dynamic equations of a multi-stage isolation system. // Int J Adv Manuf Technol. 34, (2007), pp. 1053-1061.

[19] Slavkovic, R.; Jugovic, Z.; Popovic, M. The Method of Foundation of Press Eccentric in the Object Colony Place. $/ / 31^{\text {th }}$ JUPITER Conference, Faculty of Mechanical Engineering University of Belgrade, Zlatibor, 2005.

[20] Slater, J.C.; Inman, D.J. Transfer Function Modeling of Damping mechanisms in Distributed Parameter Models. // Mechanics Research Communications. 20(4), (1993), pp. 287-292.

\section{Authors' addresses}

Radomir Slavković, Ph.D., Full Professor

Faculty of Technical Sciences in Cacak

65, Svetog Save St., 32000 Čačak, Serbia Tel. +38132302733

E-mail: radomir.slavkovic@ftn.kg.ac.rs

Aleksandar Veg, Ph.D., Full Professor

Faculty of Mechanical Engineering, University of Belgrade Kraljice Marije 16, 11120 Belgrade 35

E-mail: aleksandar.veg@rotech.rs

Nedeljko Dučić, M.Sc., Teaching Assistant

Faculty of Technical Sciences in Cacak 65, Svetog Save St., 32000 Čačak, Serbia Tel. +38132302733

E-mail: nedeljko.ducic@ftn.kg.ac.rs

Nikola Slavković, M.Sc., Teaching Assistant

Faculty of Mechanical Engineering, University of Belgrade Kraljice Marije 16, 11120 Belgrade 35

E-mail: nslavkovic@gmail.com

Jelena Baralić, M.Sc., Teaching Assistant

Faculty of Technical Sciences in Cacak

65, Svetog Save St., 32000 Čačak, Serbia

Tel. +38132302733

E-mail: jelena.baralic@ftn.kg.ac.rs

Ivan Milićević, Ph.D., Assistant Professor

Faculty of Technical Sciences in Cacak 65, Svetog Save St., 32000 Čačak, Serbia Tel. +38132302733

E-mail: ivan.milicevic@ftn.kg.ac.rs 